\title{
DENGUE HEMORRHAGIC FEVER IN THE NORTHWEST OF MEXICO: A TWO-DECADE ANALYSIS
}

\author{
Vania Serrano-Pinto* and Manuel Moreno-Legorreta \\ Centro de Investigaciones Biológicas del Noroeste, La Paz, B.C.S., Mexico
}

\begin{abstract}
Background: In Baja California Sur, Mexico, there are no records of dengue hemorrhagic fever in the state before 1995. Until now, there have been no published reports on the incidence rate. Objective: To assess the incidence rate of dengue hemorrhagic fever in Baja California Sur in the last two decades. Methods: We analyzed data on the total number of cases in the general population, incidence rate, age groups, gender, serotypes, and mortality data. Results: There were epidemiological outbreaks in 2003, 2006, 2010, 2013, and 2014. The year with the highest number of registered cases was 2003 (441 cases), with the highest incidence rate of $92.52 / 100,000$. The age groups that were primarily affected were 15-24 and 45-64 years. The serotypes of dengue virus registered during those years were DENV-1 and DENV-2. Conclusions: Dengue hemorrhagic fever in Baja California Sur has had cyclic patterns of occurrence in the last 20 years. Since 2003, the incidence rate of dengue hemorrhagic fever has greatly decreased. (REV INVES CLIN. 2017;69:152-8)
\end{abstract}

Key words: Dengue hemorrhagic fever. Diagnosis. Vector-borne diseases. Baja California Sur, Mexico.

\section{INTRODUCTION}

Dengue infection is considered the most important disease for public health in several countries. It is an acute infectious illness caused by the Dengue virus ${ }^{1}$, a member of the genus Flavivirus in the Flaviviridae family, which has four closely related serotypes, DENV-1, DENV-2, DENV-3, and DENV-42. The infection is transmitted by the bite of female mosquitoes, mainly Aedes aegypti and, to a lesser extent, Ae. albopictus, that are infected with the virus. These mosquitoes are also transmitters of chikungunya fever, yellow fever, and Zika virus infection ${ }^{4}$.

Corresponding author:

Vania Serrano-Pinto

Centro de Investigaciones Biológicas del Noroeste

Calle IPN, 195

C.P. 23096, La Paz, B.C.S., México

E-mail: vserrano04@cibnor.mx
Traditional classification of the World Health Organization (1997) defined dengue as dengue fever, dengue hemorrhagic fever, and dengue shock syndrome ${ }^{4}$. However, the dengue case definition was limited in terms of its complexity and applicability. This recognition of the limitations led to a multicenter study in different countries from which a new case definition emerged. This more recent WHO classification for dengue severity is divided into "Dengue without Warning Signs", "Dengue with Warning Signs", and "Severe Dengue"4. Despite this new classification, the previous classification of dengue fever (DF), dengue hemorrhagic fever (DHF), and dengue shock
Received for publication: 24-10-2016

Accepted for publication: 17-01-2017 
syndrome (DSS) continues to be widely used ${ }^{1}$, including in Mexico.

According to the $\mathrm{WHO}$, in 2010, 2013, and 2015, almost 2.4 million cases of dengue were reported annually. In 2015, there were large outbreaks worldwide. Each year, about 500,000 people become ill with $\mathrm{DHF}$, requiring hospitalization; about $2.5 \%$ of them die $^{3}$.

Dengue hemorrhagic fever is characterized by all the following: (i) fever lasting from 2-7 days; (ii) evidence of hemorrhagic manifestation or a positive tourniquet test; (iii) thrombocytopenia ( $\leq 100,000$ cells per $\mathrm{mm}^{3}$; and (iv) evidence of plasma leakage shown by hemoconcentration (an increase in hematocrit $\geq 20 \%$ above average for age or a decrease in hematocrit $\geq$ $20 \%$ of baseline following fluid replacement therapy), or signs of plasma leakage such as pleural effusion, ascites or hypoproteinemia ${ }^{3}$.

In Mexico, in 2015, the Ministry of Health reported 46,092 confirmed cases of DF and 8,856 confirmed cases of DHF. That year, the state of Baja California Sur (BCS) reported 571 cases of DF and three cases of DHF 5 .

Although the BCS region is in the most isolated and arid region of Mexico (Fig. 1), cases of DF have been reported for over 30 years, and their number has increased considerably in recent years ${ }^{6}$. Our main objective was to assess the incidence of $\mathrm{DHF}$ in the state of BCS from 1985 through 2015.

\section{MATERIALS AND METHODS}

\section{Study population and data}

Information on DHF was obtained from online databases of the Epidemiology General Office of the Ministry of Health in Mexico (Sistema Único de Información de la Dirección General de Epidemiología, Secretaría de Salud) for 1995 through $2015^{5}$ related to the total number of cases and incidence rate per 100,000 inhabitants. Data were analyzed for the general population by gender, age groups, mortality, and serotypes 5 . Diagnoses were confirmed by serological tests (NS1, IgM, IgG), according to the procedures set for laboratory diagnosis of DF and DHF included in the Guidelines for Epidemiological Laboratory Surveillance of Dengue (Lineamientos para la Vigilancia Epidemiológica de Dengue por Laboratorio) ${ }^{6,7}$.

\section{Statistical analysis}

Normality tests (Kolmogorov-Smirnov test) and homogeneity of variance (Levene's test) were used, with significance set at $p<0.05$. Analyses used Statistica 8.0 software to observe trends in case numbers for seven age groups in the study period. Oneway ANOVA was conducted on data having significant statistical differences, using post hoc analysis (Fisher's Least Significant Difference Test) to find data having statistical significance. ANOVA was performed within age groups across the years of study and among the age groups. To show the impact of the number of cases of DHF in years with disease outbreaks, the Exponential Decay model was run ( $y=$ $\left.a e^{-b x}\right)$.

\section{RESULTS}

Dengue hemorrhagic fever in BCS has presented cyclic patterns of occurrence in the last 20 years. There were epidemiologic outbreaks in the years 2003, 2006, 2010, 2013, and 2014. Table 1 shows cases of DHF for each month in the last two decades. The year with the highest number of registered cases was 2003 (441 cases), with the highest incidence rate of 92.52 per 100,000 . It was followed by 2013 and 2014, with 119 and 95 cases and incidence rates of 16.57 and 12.82, respectively. Table 1 also shows that the highest number of cases during the years with outbreaks occurred from August through December.

Table 2 shows the incidence rate among women, starting in 2003 when more systematic records were kept. The years 2003, 2006, 2010, 2013, and 2014 had significant peaks. Table 3 shows the same data for men. As in table 1, most cases occurred in August through December. Only in 2003 were there cases from July through November.

Table 4 shows the number of deaths and serotypes during the years since 2010. The trend in DHF over the past 20 years in the state of BCS is shown in figure 2 . The incidence rate of DHF by age group during disease outbreaks is shown in figure 3. ANOVA analysis shows a sharp increase in 2003 and, to a lesser extent, during 2006, 2010, 2013, and 2014. 
Figure 1. Study area.

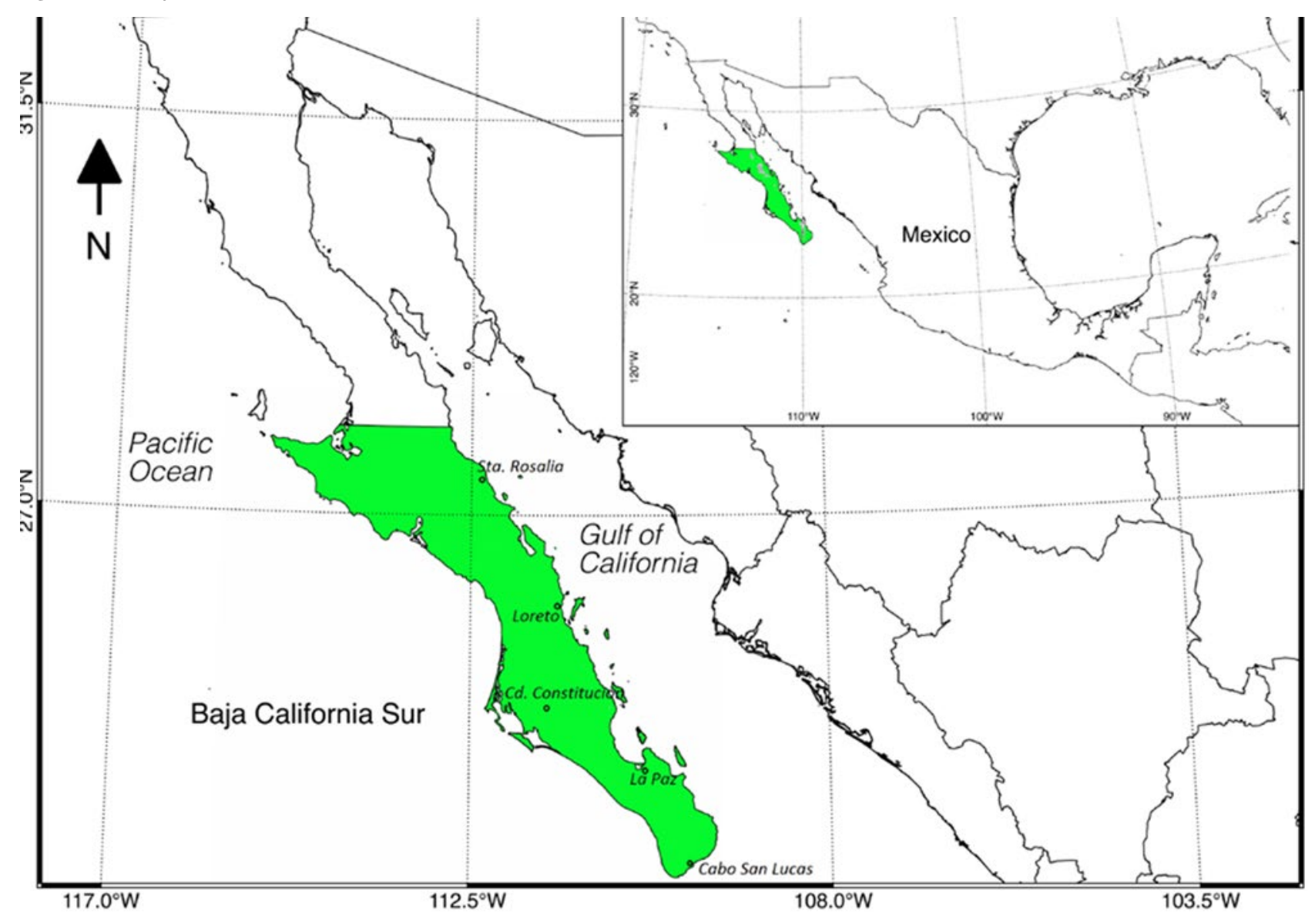

In 2003 and 2013, the most affected age group was 45-64 years, and in 2006, 2010, and 2014, it was the group of 15-24 years of age.

The Exponential Decay model to calculate the impact of the number of cases of DHF in years with disease outbreaks showed a determination coefficient of 0.9385 (Fig. 4).

\section{DISCUSSION}

While cases of DF have been recorded in Baja California Sur since 1985, it was not until 1995 that the first case of DHF occurred in the region ${ }^{5}$. Although the epidemiological outbreaks of DF from 2003 onward occurred in the same years as the epidemiological outbreaks of DHF, the patterns of behavior of both diseases were different. Moreno-Legorreta, et al. reported that the number of cases of DF increased more than 75-fold in the last 12 years (2003-2014), while the DHF cases peaked in 2003 (441 cases) ${ }^{7}$.

During the years of epidemiologic outbreaks, a greater number of DHF cases were recorded during the months of August through December in the general population, with cases peaking in September through November. This behavior is consistent with observations throughout Mexico during the 2000-2009 decade $^{8}$. There is a possibility that the highest incidence rate in DHF cases present in autumn is due to the ecology of the mosquito vector, as mentioned by Tovar, et al. ${ }^{10}$; they observed that, between September and November, mosquitoes laid the greatest numbers of eggs in BCS.

Our results show a higher incidence of DHF in women than in men during 2003-2014. Moreno-Legorreta, et al. also found higher rates of DF among women in the last 12 years $(2003-2014)^{7}$. 
Table 1. Cases of dengue hemorrhagic fever in Baja California Sur, Mexico by month, from 1995 through 2015

\begin{tabular}{|c|c|c|c|c|c|c|c|c|c|c|c|c|c|c|}
\hline Year & Incidence* & Total & J & $F$ & $\mathrm{M}$ & A & $M$ & J & J & A & $S$ & 0 & $\mathrm{~N}$ & D \\
\hline 2015 & 0.39 & 3 & 2 & 0 & 1 & 0 & 0 & 0 & 0 & 0 & 0 & 0 & 0 & 0 \\
\hline 2014 & 12.82 & 95 & 5 & 1 & 1 & 1 & 3 & 5 & 4 & $\underline{31}$ & $\underline{24}$ & $\underline{9}$ & $\underline{10}$ & 1 \\
\hline 2013 & 16.57 & 119 & 1 & 0 & 0 & 0 & 0 & 1 & 1 & $\underline{4}$ & $\underline{10}$ & $\underline{52}$ & $\underline{37}$ & $\underline{13}$ \\
\hline 2012 & 2.01 & 14 & 0 & 0 & 0 & 0 & 0 & 0 & 0 & 0 & 1 & 1 & 7 & 5 \\
\hline 2011 & 1.18 & 7 & 4 & 0 & 0 & 0 & 0 & 0 & 0 & 0 & 1 & 0 & 1 & 1 \\
\hline 2010 & 14.16 & 79 & 5 & 3 & 2 & 0 & 1 & 6 & 2 & 3 & $\underline{10}$ & $\underline{17}$ & $\underline{18}$ & $\underline{12}$ \\
\hline 2009 & 3.71 & 21 & 0 & 0 & 0 & 0 & 0 & 0 & 0 & 0 & 2 & 3 & 7 & 9 \\
\hline 2008 & 2.36 & 13 & 0 & 1 & 0 & 0 & 1 & 0 & 1 & 1 & 1 & 4 & 3 & 1 \\
\hline 2007 & 0.95 & 5 & 0 & 0 & 0 & 0 & 0 & 1 & 1 & 0 & 1 & 1 & 1 & 0 \\
\hline 2006 & 5.24 & 27 & 0 & 0 & 0 & 0 & 0 & 1 & 0 & 0 & $\underline{6}$ & $\underline{10}$ & $\underline{6}$ & $\underline{4}$ \\
\hline 2005 & 0.40 & 2 & 1 & 0 & 0 & 0 & 0 & 0 & 0 & 0 & 0 & 1 & 0 & 0 \\
\hline 2004 & 0 & 0 & 0 & 0 & 0 & 0 & 0 & 0 & 0 & 0 & 0 & 0 & 0 & 0 \\
\hline 2003 & 92.52 & 441 & 0 & 0 & 0 & 0 & 0 & 0 & $\underline{32}$ & $\underline{93}$ & $\underline{90}$ & $\underline{154}$ & $\underline{68}$ & 4 \\
\hline 2002 & 0 & 0 & 0 & 0 & 0 & 0 & 0 & 0 & 0 & 0 & 0 & 0 & 0 & 0 \\
\hline 2001 & 0 & 0 & 0 & 0 & 0 & 0 & 0 & 0 & 0 & 0 & 0 & 0 & 0 & 0 \\
\hline 2000 & 0 & 0 & 0 & 0 & 0 & 0 & 0 & 0 & 0 & 0 & 0 & 0 & 0 & 0 \\
\hline 1999 & 0 & 0 & 0 & 0 & 0 & 0 & 0 & 0 & 0 & 0 & 0 & 0 & 0 & 0 \\
\hline 1998 & 0 & 0 & 0 & 0 & 0 & 0 & 0 & 0 & 0 & 0 & 0 & 0 & 0 & 0 \\
\hline 1997 & 0.24 & 1 & 0 & 0 & 0 & 0 & 0 & 0 & 0 & 0 & 0 & 0 & 0 & 1 \\
\hline 1996 & 0.50 & 2 & 0 & 0 & 0 & 0 & 0 & 0 & 0 & 0 & 2 & 0 & 0 & 0 \\
\hline 1995 & 0.26 & 1 & 0 & 0 & 0 & 0 & 0 & 0 & 0 & 0 & 0 & 0 & 1 & 0 \\
\hline TOTAL & 153.31 & 732 & 11 & 4 & 2 & 0 & 2 & 9 & 37 & 101 & 124 & 243 & 149 & 50 \\
\hline
\end{tabular}

Source: SUIVE/DGE/Secretaría de Salud/Estados Unidos Mexicanos, $2015^{8}$.

Years with outbreaks are in bold typeface. Months with the highest number of cases are underlined.

*Incidence rate for each 100,000 inhabitants.

Table 2. Cases of dengue hemorrhagic fever in Baja California Sur, Mexico, among women, by month, from 2003 through 2015

\begin{tabular}{lcccccccccccccc}
\hline Year & Incidence* & Total & J & F & M & A & M & J & J & A & S & O & N & D \\
\hline 2015 & 0.27 & 1 & 0 & 0 & 1 & 0 & 0 & 0 & 0 & 0 & 0 & 0 & 0 & 0 \\
2014 & 10.71 & 39 & 0 & 0 & 0 & 1 & 1 & 3 & 4 & $\underline{12}$ & $\underline{11}$ & $\underline{3}$ & $\underline{4}$ & 0 \\
2013 & 19.58 & 69 & 0 & 0 & 0 & 0 & 0 & 0 & 1 & 3 & $\underline{10}$ & $\underline{25}$ & $\underline{23}$ & $\underline{7}$ \\
2012 & 1.76 & 6 & 0 & 0 & 0 & 0 & 0 & 0 & 0 & 0 & 1 & 0 & 2 & 3 \\
2011 & 1.07 & 3 & 3 & 0 & 0 & 0 & 0 & 0 & 0 & 0 & 0 & 0 & 0 & 0 \\
2010 & 12.71 & 35 & 2 & 1 & 1 & 0 & 1 & 2 & 1 & 2 & $\underline{3}$ & $\underline{9}$ & $\underline{7}$ & $\underline{6}$ \\
2009 & 2.97 & 8 & 0 & 0 & 0 & 0 & 0 & 0 & 0 & 0 & 0 & 2 & 3 & 3 \\
2008 & 2.66 & 7 & 0 & 0 & 0 & 0 & 0 & 0 & 1 & 0 & 0 & 3 & 2 & 1 \\
2007 & 1.17 & 3 & 0 & 0 & 0 & 0 & 0 & 0 & 0 & 0 & 1 & 1 & 1 & 0 \\
2006 & 5.19 & 13 & 0 & 0 & 0 & 0 & 0 & 1 & 0 & 0 & 1 & $\underline{6}$ & $\underline{3}$ & $\underline{2}$ \\
2005 & 0.82 & 2 & 1 & 0 & 0 & 0 & 0 & 0 & 0 & 0 & 0 & 1 & 0 & 0 \\
2004 & 0 & 0 & 0 & 0 & 0 & 0 & 0 & 0 & 0 & 0 & 0 & 0 & 0 & 0 \\
2003 & 108.5 & 252 & 0 & 0 & 0 & 0 & 0 & 0 & $\underline{14}$ & $\underline{56}$ & $\underline{58}$ & $\underline{87}$ & $\underline{33}$ & $\underline{4}$ \\
TOTAL & 167.41 & 438 & 6 & 1 & 2 & 1 & 2 & 6 & 21 & 73 & 85 & 137 & 78 & 26 \\
\hline
\end{tabular}

Source: SUIVE/DGE/Secretaría de Salud/Estados Unidos Mexicanos, 2015.

Years with outbreaks are in bold typeface. Months with the highest number of cases are underlined.

*Incidence rate for each 100,000 inhabitants.

We reviewed information on the serotypes of dengue virus (DENV) identified in this region ${ }^{5}$. During 2003, there were a large number of DHF cases; however, there is no record of the serotypes or the number of related deaths, making it difficult to conclude whether one or more serotypes were present during that year. Gaxiola-Robles, et al. ${ }^{11}$ evaluated the serotypes identified in Mexico during 30 years (1980-2009); during 2003, serotypes DENV-2 and DENV-3 were present, noting that the coupling of DENV-2 of Asian origin 
Table 3. Cases of dengue hemorrhagic fever in Baja California Sur, Mexico, among men, by month, from 2003 through 2015.

\begin{tabular}{lcccccccccccccc}
\hline Year & Incidence* & Total & J & F & M & A & M & J & J & A & S & O & N & D \\
\hline 2015 & 0.52 & 2 & 2 & 0 & 0 & 0 & 0 & 0 & 0 & 0 & 0 & 0 & 0 & 0 \\
2014 & 14.85 & 56 & 5 & 1 & 1 & 0 & 2 & 2 & 0 & $\underline{19}$ & $\underline{13}$ & $\underline{6}$ & $\underline{6}$ & 1 \\
2013 & 13.67 & 50 & 1 & 0 & 0 & 0 & 0 & 1 & 0 & 1 & 0 & $\underline{27}$ & $\underline{14}$ & 6 \\
2012 & 2.26 & 8 & 0 & 0 & 0 & 0 & 0 & 0 & 0 & 0 & 0 & 1 & 5 & 2 \\
2011 & 1.28 & 4 & 1 & 0 & 0 & 0 & 0 & 0 & 0 & 0 & 1 & 0 & 1 & 1 \\
2010 & 14.48 & 44 & 3 & 2 & 1 & 0 & 0 & 4 & 1 & 1 & $\underline{7}$ & $\underline{8}$ & $\underline{11}$ & $\underline{6}$ \\
2009 & 4.39 & 13 & 0 & 0 & 0 & 0 & 0 & 0 & 0 & 0 & 2 & 1 & 4 & 6 \\
2008 & 2.08 & 6 & 0 & 1 & 0 & 0 & 1 & 0 & 0 & 1 & 1 & 1 & 1 & 0 \\
2007 & 0.71 & 2 & 0 & 0 & 0 & 0 & 0 & 1 & 1 & 0 & 0 & 0 & 0 & 0 \\
2006 & 5.28 & 14 & 0 & 0 & 0 & 0 & 0 & 0 & 0 & 0 & $\underline{5}$ & $\underline{4}$ & $\underline{3}$ & $\underline{2}$ \\
2005 & 0 & 0 & 0 & 0 & 0 & 0 & 0 & 0 & 0 & 0 & 0 & 0 & 0 & 0 \\
2004 & 0 & 0 & 0 & 0 & 0 & 0 & 0 & 0 & 0 & 0 & 0 & 0 & 0 & 0 \\
2003 & 77.33 & 189 & 0 & 0 & 0 & 0 & 0 & 0 & 18 & $\underline{37}$ & $\underline{32}$ & $\underline{67}$ & $\underline{35}$ & 0 \\
TOTAL & 123.18 & 388 & 12 & 4 & 2 & 0 & 3 & 8 & 20 & 59 & 61 & 115 & 80 & 24 \\
\hline
\end{tabular}

Source: SUIVE/DGE/Secretaría de Salud/Estados Unidos Mexicanos, 2015.

Years with outbreaks are in bold typeface. Months with the highest number of cases are underlined.

*Incidence rate for each 100,000 inhabitants.

Table 4. Cases of dengue hemorrhagic fever, mortality and serotypes, in Baja California Sur, Mexico, from 1995 through 2015

\begin{tabular}{|c|c|c|c|}
\hline Year & Dhf & Mortality & Serotypes \\
\hline 2015 & 3 & 0 & 1 \\
\hline 2014 & 95 & $\underline{4}$ & 1,2 \\
\hline 2013 & 119 & $\underline{3}$ & 1,2 \\
\hline 2012 & 14 & 0 & 1,2 \\
\hline 2011 & 7 & 0 & 1 \\
\hline 2010 & 79 & $\underline{1}$ & 1 \\
\hline 2009 & 21 & 0 & ND \\
\hline 2008 & 13 & $\underline{1}$ & ND \\
\hline 2007 & 5 & ND & ND \\
\hline 2006 & 27 & ND & ND \\
\hline 2005 & 2 & ND & ND \\
\hline 2004 & 0 & ND & ND \\
\hline 2003 & 441 & ND & ND \\
\hline 2002 & 0 & ND & ND \\
\hline 2001 & 0 & ND & ND \\
\hline 2000 & 0 & ND & ND \\
\hline 1999 & 0 & ND & ND \\
\hline 1998 & 0 & ND & ND \\
\hline 1997 & 1 & ND & ND \\
\hline 1996 & 2 & ND & ND \\
\hline 1995 & 1 & ND & ND \\
\hline
\end{tabular}

Source: SINAVE/DGE/SALUD/Sistema Especial de Vigilancia Epidemiológica de Dengue, $2015^{6}$.

Years with outbreaks are in bold typeface. Years with number of deaths are underlined. Years with serotypes information are in italics. Years with no data (ND).
Figure 2. Incidence rate of dengue hemorrhagic fever for 20 years (1995-2015) in the state of Baja California Sur, Mexico (annual average per 100,000 inhabitants).

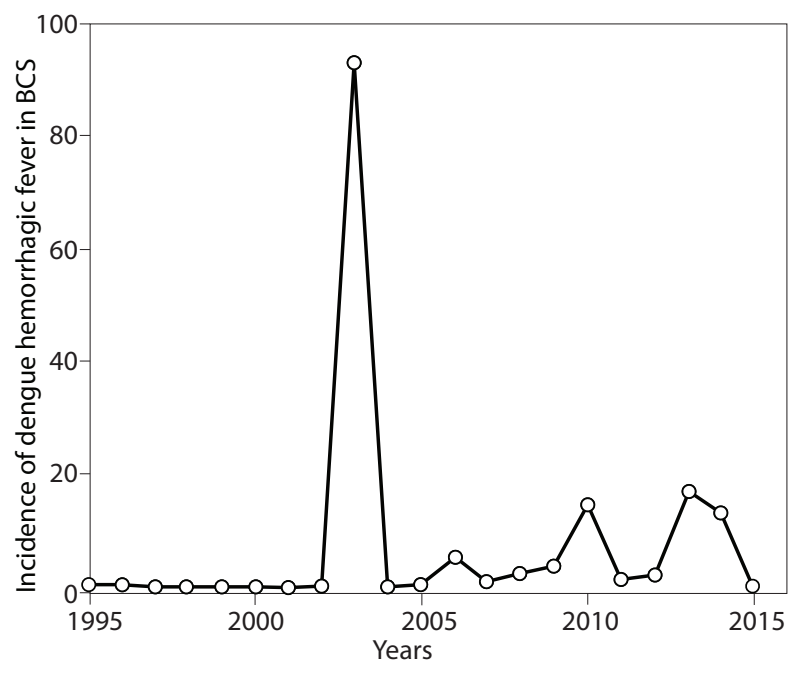

with DENV-3 of Asian or African origin may have caused the increase in deaths from 1994 to 2009.

In BCS, serotypes were first recorded in 2010, with DENV-1 being the cause in 79 cases and one death. In 2011, there were seven cases, no deaths, and only DENV-1 was identified. From 2012 to 2014, DENV-1 and DENV-2 were present ${ }^{5}$. The high incidence rates of DHF during 2013 (16.57 per 100,000), with 119 cases and three deaths, and 2014 (12.82 per 100,000), with 95 cases and four deaths, were possibly due to the introduction and simultaneous circulation of both 
Figure 3. Incidence rate of dengue hemorrhagic fever in different age groups in years with outbreaks in the State of Baja California Sur (annual average per 100,000 inhabitants). Different letters on the bars indicate significant statistical differences ( $p<0.05$ ).
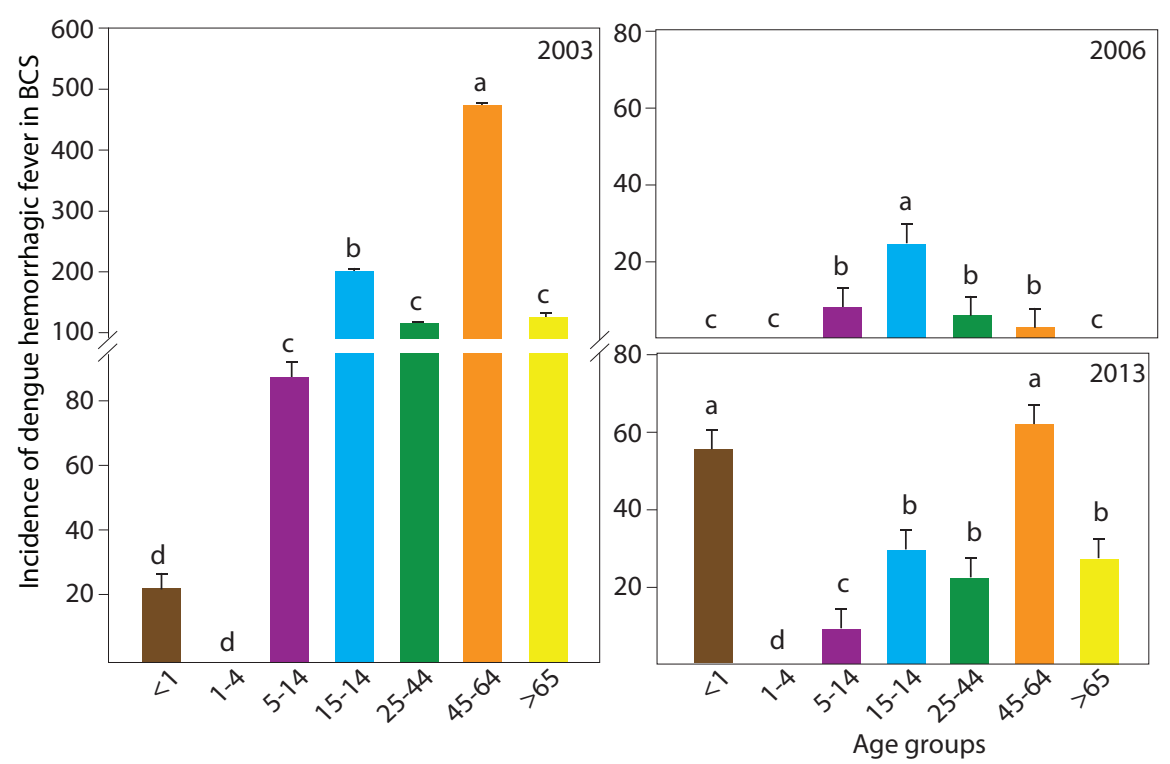

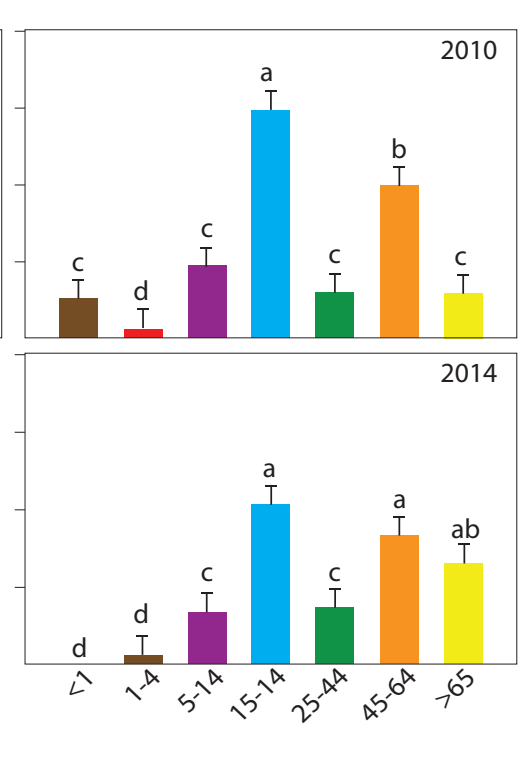

Figure 4. Exponential Negative Decay model for the incidence rate of dengue hemorrhagic fever in years with outbreaks in the State of Baja California Sur.

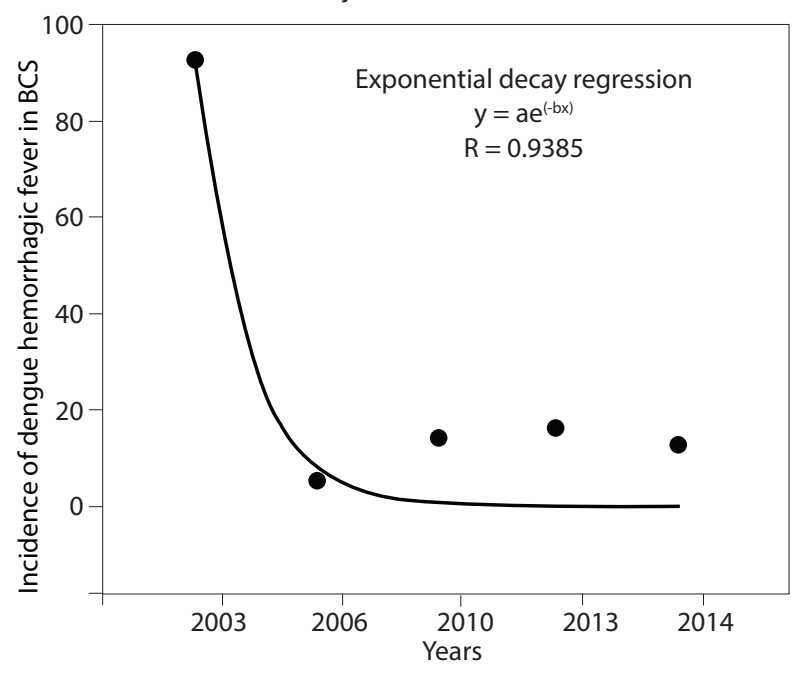

serotypes. It is hypothesized that the simultaneous presence of two or more serotypes in a region exerts an enhancing effect. Falcón, et al. states that if several serotypes are present at the same time in a region, these may increase the chances of a higher transmission and epidemic episodes with greater frequency ${ }^{12}$. Other authors mention that it is possible that the presence of more virulent genotypes or hyperendemicity (presence of several serotypes in the same area) increases the likelihood of severe forms of the disease ${ }^{12-14}$.
However, although there were a large number of DHF cases in 2013 and 2014, few deaths occurred, most likely due to the timely care provided by health centers, or to the possibility that the genotypes were not as virulent. During 2015, three cases of DHF were recorded and the only serotype detected was DENV-1, with no deaths.

Our results also show that epidemiologic outbreaks in 2006, 2010, and 2014 caused the highest morbidity among persons 15-24 years old. In the outbreaks of 2003 and 2013, the most affected age group was 4564 years. These results are consistent with the behavior of the incidence rate of cases of DF in the same region and the same years ${ }^{6}$. This trend has been recently reported by Torres-Galicia, et al. in an analysis of DF and DHF in Mexico from 1990 through 20119. They found that in the first decade (2000-2009), the highest incidence rate of DHF occurred among young adults 15-24 years old. This behavior is similar to records in other countries, such as Puerto Rico, Brazil, and Sri Lanka, with a large number of adult patients ${ }^{15-17}$. We suggest that more attention be paid to this age group because DHF negatively impacts a country's economy from loss of productivity and medical expenses, as mentioned by Añez, et al. in a study in Venezuela ${ }^{18}$.

The Exponential Decay model is used to make future predictions of possible outbreaks of disease. In this 
study, the number of cases of DHF in years with disease outbreaks showed a negative correlation, which means that an outbreak of DHF is not likely to occur in this region in the near future.

In conclusion, this study revealed that DHF in BCS is cyclic, as is DF. However, both illnesses do not show the same behavior, since the incidence rate of DF has increased in recent years, and DHF has declined since 2013 when there were 119 cases with only three cases in 2015.

\section{ACKNOWLEDGEMENTS}

We thank the Departamento de Estadística, Dirección General de Planeación de la Secretaria de Salud, BCS; Departamento de Vigilancia Epidemiológica, Subdirección de Medicina Preventiva de la Dirección de los Servicios de Salud, BCS; and Programa de Vectores de la Secretaría de Salud, BCS, for providing data and other information. Funding for this study was provided by the Centro de Investigaciones Biológicas del Noroeste (CIBNOR project PPAC-2015), Baja California Sur, Mexico.

\section{REFERENCES}

1. World Health Organization. Dengue guidelines for diagnosis, treatment, prevention and control. Programme for TDR, Genéve, Switzerland. 2009. Available at: http://www.who.int/tdr/publications/documents/dengue-diagnosis.pdf
2. Leitmeyer K, Vaughn D, Watts D, et al. Dengue virus structural differences that correlate with pathogenesis. J Virol. 1999;73:4738-47.

3. World Health Organization. Dengue y dengue grave. 2016. Available at: http://www.who.int/mediacentre/factsheets/fs117/es/

4. Centers for Disease Control and Prevention. 2013. Available at: https://www.cdc.gov/dengue/clinicallab/casedef.html.

5. SINAVE/DGE/SALUD/Sistema Especial de Vigilancia Epidemiológica de Dengue. Secretaría de Salud. 2016. Available at: http://www.epidemiologia.salud.gob.mx/informes/informesh /2015/dengue-semanas.html.

6. Moreno-Legorreta M, Díaz-Castro S, Ortega-Rubio A, TovarZamora I, Serrano-Pinto V. Decades of experience in the diagnosis of dengue fever in the Northwest of Mexico. Rev Invest Clin. 2015;67:372-8

7. SUIVE/DGE/Secretaría de Salud/Estados Unidos Mexicanos. Anuarios de Morbilidad. Sistema Nacional de Vigilancia Epidemiológica. Sistema Único de Información de la Dirección General de Epidemiología (DGEPI). Secretaría de Salud. 2015. Available at: http://www.epidemiologia.salud.gob.mx/anuario/html/anuarios.html.

8. Torres-Galicia I, Cortés-Poza D, Becker I. [Dengue in Mexico: an analysis of two decades]. Gac Med Mex. 2014;150:122-7.

9. Tovar I, Ramos A, Servín R. Entomological indicators to assess larval Aedes aegypti (Linnaeus, 1762) control in Baja California Sur, Mexico. Southwest Entomol. 2015;40:81-96.

10. Gaxiola-Robles R, Celis A, Serrano-Pinto V, Orozco-Valerio MJ, Zenteno-Savín T. Mortality trend by dengue in Mexico 1980 to 2009. Rev Invest Clin. 2012;64:444-51.

11. Falcón-Lezama JA, Ramos C, Zúñiga J, et al. HLA class I and II polymorphisms in 291 Mexican Mestizo patients with dengue fever. Acta Trop. 2009;112:193-7.

12. Halstead SB. Pathogenesis of dengue: challenges to molecular biology. Science. 1988;239:476-81.

13. Valero N. [Toward integrated dengue control ]. Invest Clin. 2002:43:141-4.

14. Mairuhu AT, Wagenaar J, Brandjes DP, van Gorp EC. Dengue: an arthropod-borne disease of global importance. Eur J Clin Microbiol Infect Dis. 2004;23:425-33.

15. Rigau-Perez JG, Vorndam AV, Clark GG. The dengue and dengue hemorrhagic fever epidemic in Puerto Rico, 1994-1995. Am J Trop Med Hyg. 2001;64:67-74.

16. Siqueira JB Jr, Martelli CM, Coelho GE, Simplicio AC, Hatch DL. Dengue and dengue hemorrhagic fever, Brazil, 1981-2002. Emerg Infect Dis. 2005;11:48-53.

17. Malavige GN, Velathanthiri VG, Wijewickrama ES, et al. Patterns of disease among adults hospitalized with dengue infections. Q J Med. 2006;99:299-305.

18. Añez G, Balza R, Valero N, Larreal Y. [Economic impact of dengue and dengue hemorrhagic fever in the State of Zulia, Venezuela, 1997-2003]. Rev Panam Salud Pública. 2006;19:314-20. 